\title{
Do general practitioner hospitals reduce the utilisation of general hospital beds? Evidence from Finnmark county in north Norway
}

\author{
Ivar Aaraas, Olav Helge Førde, Ivar Sønbø Kristiansen, Hasse Melbye
}

\begin{abstract}
Study objective-To assess whether populations with access to general practitioner hospitals (GP hospitals) utilise general hospitals less than populations without such access.

Design-Observational study comparing the total rates of admissions and of occupied bed days in general hospitals between populations with and without access to GP hospitals. Comparisons were also made separately for diagnoses commonly encountered in GP hospitals.

Setting-Two general hospitals serving the population of Finnmark county in north Norway.

Patients-35 435 admissions based on five years' routine recordings from the two hospitals.

Main results-The total rate of admission to general hospitals was lower in peripheral municipalities with a GP hospital than in central municipalities without this kind of institution, $26 \%$ and $28 \%$ lower for men and women respectively. The corresponding differences were $38 \%$ and $52 \%$, when analysed for occupied bed days. The differences were most pronounced for patients with respiratory diseases, cardiac failure, and cancer who are primarily or intermediately treated or cared for in GP hospitals, and for patients with stroke and fractures, who are regularly transferred from general hospitals to GP hospitals for longer term follow up care.

Conclusion-GP hospitals seem to reduce the utilisation of general hospitals with respect to admissions as well as occupied bed days.
\end{abstract}

(F Epidemiol Community Health 1998;52:243-246)

In Norway, general practitioner hospitals (GP hospitals) are small medical institutions on a level between primary care and general hospitals. They contain from two to around 20 beds and are usually located together with the GPs' surgery and the local nursing home in a joint

Institute of

Community Medicine, University of Tromsø, N-9037 Tromsø, Norway

Correspondence to: Dr Aaraas.

Accepted for publication 5 June 1997 follow up care had the longest stays in the GP hospitals. Based on these findings it seems reasonable to anticipate that hospital admission rates are lower and that length of stay are shorter for populations with access to GP hospitals than for those without. An eight week survey indicated that this was the case particularly for conditions commonly cared for in GP hospitals. $^{2}$ To explore this issue further, we have studied general hospital utilisation for a longer period in the same geographical area. The county of Finnmark is well suited for such a study because it still has 16 GP hospitals in active use and because $90 \%$ of GP hospital patients referred to higher level hospitals are admitted to the two county general hospitals. ${ }^{2}$

The aim of the study was to assess whether populations with access to a GP hospital utilise general hospital beds at a lower rate than populations without such access, particularly with respect to conditions commonly treated in GP hospitals.

\section{Methods}

Routine hospital data for the five year period from 1 January 1990 to 31 December 1994 were collected. The material includes admissions to both county general hospitals and comprises 35435 stays over 224969 days, corresponding to an average length of 6.3 days per stay. Admissions because of administrative/ non-disease reasons and patients with obstetric or missing diagnoses or with residence outside the county hospital area were excluded. Based on previous studies of medical conditions frequently treated in GP hospitals, ${ }^{12}$ we classified certain ICD-9 diagnoses as "GP hospital diagnoses" (see table 2). Calculation of rates was based on the population size of Finnmark in the middle of the five year period. This included a total of 75975 persons among whom 55409 lived distant from the hospital (one to four hours travel time away) in 16 municipalities with a GP hospital, while 20566 lived in three municipalities closer to the general hospital and without access to a GP hospital. The age distribution and average age were almost identical in the population with (mean $=34.6$ years) and without (mean $=35.6$ years) access to GP beds. Epi- Info, database and statistics system, were used in the statistical analysis. ${ }^{3}$ Age differences were tested by Student's $t$ test. Age standardisation was done by the direct method, ${ }^{4}$ with the total population of Finnmark as the reference population. To test differences in admission rates between corresponding subpopulations from different 


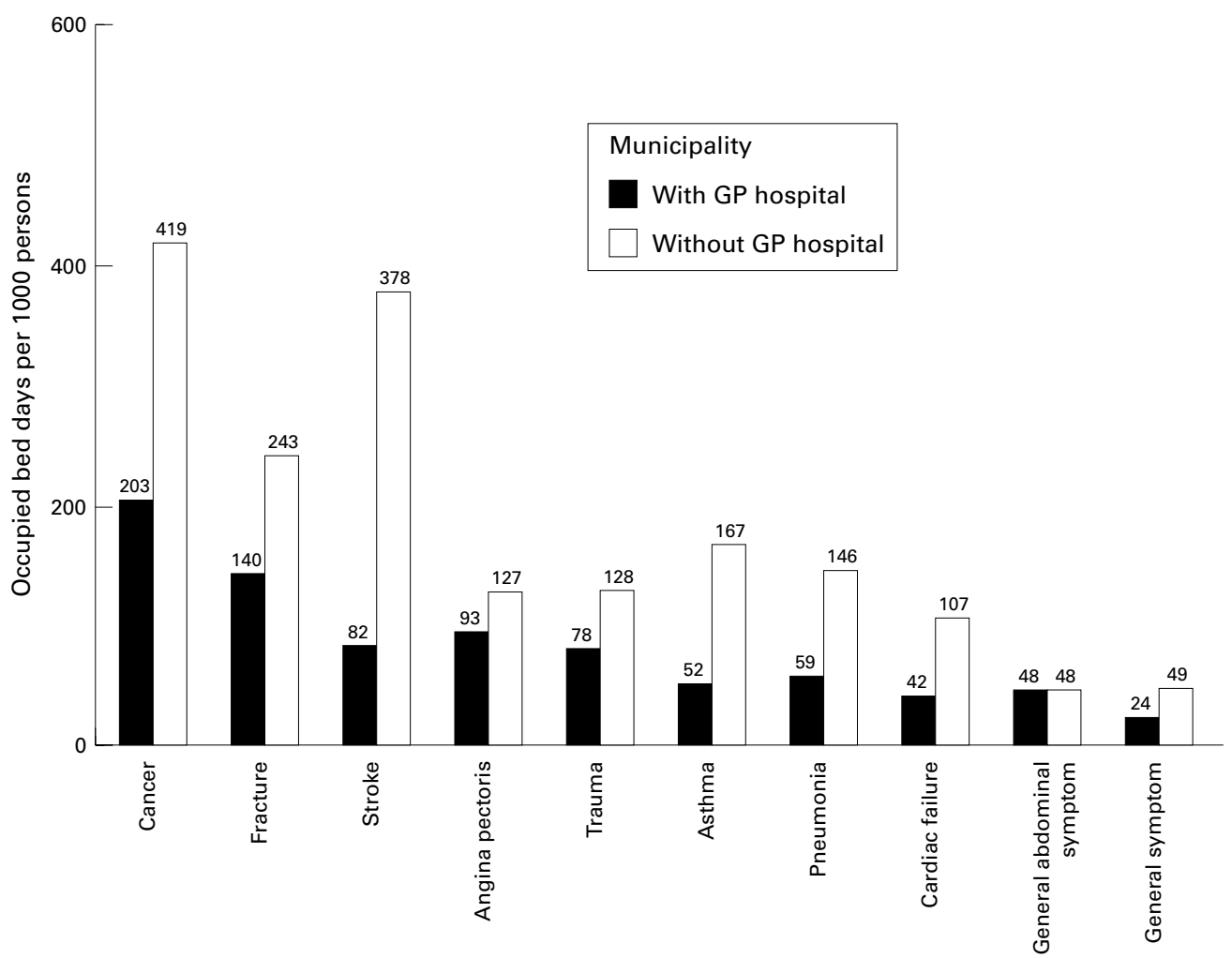

Figure 1 Occupied bed days in general hospitals in Finnmark per 1000 persons (1990-1994) for populations from municipalities with and without GP hospitals according to "GP hospital diagnoses" (conditions commonly treated in GP hospitals), adjusted for age.

municipalities $\chi^{2}$ (goodness of fit for proportions) was applied.

\section{Results}

Standardised for age, the total hospital admission rate was $26 \%$ lower for men (420 $v 566$ admissions per 1000 inhabitants over five years) and $28 \%$ lower for women ( $415 v 578$ ) in municipalities with a GP hospital than in those without (table 1). The difference was statistically significant for all age/sex groups and highly significant for those above 15 years $(\mathrm{p}<0.0001)$. The age adjusted rates of occupied bed days were 2407 and 2440 for men and women respectively in municipalities with a GP hospital and 3912 and 4698 in those without. This represents a $38 \%$ and $52 \%$ lower rate of occupied bed days for men and women, respectively. The differences were most pronounced for those aged 50 and older $(73 \%$ and $71 \%$ lower among those aged 80 and over). The rates of admission were significantly lower $(p<0.05 \%)$ for nine of 10 selected "GP hospital diagnoses" in municipalities with a GP hospital than in those without. General abdominal symptoms were an exception $(\mathrm{p}=0.15)$. When all "GP hospital diagnoses" and all other diagnoses were analysed as entire groups the rates were also lower in municipalities with a GP hospital $(\mathrm{p}<0.001)$. The differences in length of stay were striking for most "GP hospital diagnoses" (table 2). This was particularly true for patients with cancer, cardiac failure, stroke, pneumonia, and fractures, while there was no difference with respect to angina pectoris, general symptoms, and traumas. Highly significant age differences between patients from communities with and without GP hospitals were demonstrated for several "GP hospital diagnoses", with stroke (69.6 $v 73.9$ years) and asthmatic disorders ( $50.9 v 57.0$ years) as the two most prominent examples, while no significant age difference was found for patients with cancer, general abdominal symptoms, and traumas. The rates of occupied bed days in populations with GP hospitals were less than $50 \%$ of the rates in populations without GP hospitals for five of 10 "GP hospital diagnoses" (fig 1). The greatest differences were for stroke and asthmatic disorders with $78 \%$ and $69 \%$ lower rates in populations with a GP hospital. The highest rates of occupied bed days were found for the only municipality which had neither GP hospital nor a general hospital in its locality.

\section{Discussion}

This study strongly indicates that GP hospitals result in lower utilisation of general hospital services. This has previously been suggested in several studies..$^{5-10}$ According to estimates from a hospital medical department of Finnmark, ${ }^{5}$ patients from municipalities with a GP hospital occupied 0.38 bed days per inhabitant per year compared with 1.19 bed days from the general hospital municipality. In Oxfordshire the rate of use of medical and geriatric beds in general hospitals by practice populations with access to general practitioner beds was about half that of populations without such access. ${ }^{6}$ Our results add to previous findings by showing that the GP hospital effect is mainly linked to diagnoses 
commonly treated in GP beds, and that it results from both reduced admission rates and from a reduced occupied bed day period.

The study was based on routine data collected for the management of the two general hospitals. The data covered five years with small variation in total utilisation from year to year. We believe that the data necessary for adequate patient management like date of birth, admission and discharge as well as patient addresses would be largely correct. Recording of diagnoses may be more inaccurate, but we have no indication of any bias affecting the study. Missing diagnoses, representing altogether 1395 stays during the five year period, were excluded from the material. Among those excluded because of missing diagnoses, patients from municipalities without GP hospitals were over-represented and they used $80 \%$ of the excluded care days. This would suggest that we have underestimated the difference between municipalities with and without GP hospitals.

In Finnmark the travel time to the hospital varies from a few minutes to up to four hours. Unfortunately, the municipalities with a GP hospital are also those most distant from the general hospitals. This means that the distance to general hospitals is a confounder, which was demonstrated in a preliminary multivariate analysis. Because of the high correlation between travel time and the locality of a GP hospital the regression model turned out to be unstable and was omitted. In several studies hospital admission rates have been found to be higher from central communities with a hospital compared with peripheral communities. ${ }^{11-13}$ However, none of these studies has shown any linear association between distance, in terms of travel time, and use of hospital beds. Roughly, it seems that two categories of distance from hospitals, "close" or "remote", are associated with high or low use, respectively. One study suggested that the difference in admission rates between hospital communities and more distant communities was not because of geographical distance, but a social one. ${ }^{11}$ An analysis of all admissions to Norwegian hospitals in 1991 showed that patients up to the age of 65 living in a municipality with a hospital stayed in hospitals just as long as corresponding patients from municipalities without a hospital..$^{13}$ For older patients there were significant differences between central and peripheral municipalities. Finnmark seems to be special in the sense that striking differences between central and peripheral municipalities are found for all age groups. In addition the most pronounced differences were seen for diagnoses frequently encountered in GP hospitals. The eight week study of admissions to general practitioner hospitals, ${ }^{2}$ indicates the relative influence of these beds. The rate of admissions to general hospitals was $35 \%$ lower from distant populations if admissions to GP beds were excluded from the estimate, but still $22 \%$ lower if these admissions were included. In terms of utilisation of hospital bed days, the difference was even greater. This does not rule out the effect of geographical distance, but strongly suggests

Table 1 Admissions and occupied bed days per 1000 inhabitants in general hospitals in Finnmark from municipalities with and without GP hopsitals, 1990-1994, according to sex and age

\begin{tabular}{|c|c|c|c|c|c|c|c|c|}
\hline \multirow[b]{3}{*}{ Age groups (years) } & \multicolumn{4}{|c|}{ Admissions/1000 inhabitants } & \multicolumn{4}{|c|}{ Occupied bed days/1000 inhabitants } \\
\hline & \multicolumn{2}{|c|}{$\begin{array}{l}\text { Municipality with GP } \\
\text { hospital }\end{array}$} & \multicolumn{2}{|c|}{$\begin{array}{l}\text { Municipality without GP } \\
\text { hospital }\end{array}$} & \multicolumn{2}{|c|}{$\begin{array}{l}\text { Municipality with } G P \\
\text { hospital }\end{array}$} & \multicolumn{2}{|c|}{$\begin{array}{l}\text { Municipality without GP } \\
\text { hospital }\end{array}$} \\
\hline & Men & Women & Men & Women & Men & Women & Men & Women \\
\hline $0-14$ & 304.8 & 227.5 & 406.4 & 253.4 & 995.2 & 767.6 & 1294.3 & 775.2 \\
\hline $15-29$ & 186.6 & 229.6 & 255.0 & 313.1 & 654.0 & 777.9 & 911.4 & 1203.1 \\
\hline $30-49$ & 269.8 & 366.3 & 341.1 & 456.6 & 1293.6 & 1598.2 & 1556.3 & 1974.7 \\
\hline $50-69$ & 719.5 & 617.5 & 981.6 & 741.6 & 4922.4 & 3960.2 & 7092.5 & 5844.9 \\
\hline $70-79$ & 1596.6 & 1148.5 & 1900.5 & 1687.3 & 11998.5 & 9228.5 & 19354.4 & 22252.3 \\
\hline$\geqslant 80$ & 1676.9 & 1302.2 & 3201.1 & 2414.8 & 13183.4 & 10262.5 & 48126.4 & 35266.5 \\
\hline \multicolumn{9}{|l|}{ Total } \\
\hline Crude rate & 417.7 & 426.9 & 574.5 & 597.1 & 2386.3 & 2399.3 & 4020.0 & 4974.8 \\
\hline Age adjusted rate & 420.0 & 415.3 & 566.1 & 577.7 & 2406.7 & 2439.5 & 3912.1 & 4698.4 \\
\hline
\end{tabular}

Table 2 Number, rate, and length of stays in general hospitals of Finnmark for patients from municipalities with and without GP hospitals, 1990-1994, according to diagnoses

\begin{tabular}{|c|c|c|c|c|c|c|c|c|}
\hline \multirow{3}{*}{$\begin{array}{l}\text { Diagnoses } \\
\text { "GP hospital diagnoses" (ICD-9 numbers): }\end{array}$} & \multicolumn{4}{|c|}{$\begin{array}{l}\text { Municipality with GP hospital } \\
\text { general hospital stays }\end{array}$} & \multicolumn{4}{|c|}{$\begin{array}{l}\text { Municipality without GP hospital } \\
\text { general hospital stays }\end{array}$} \\
\hline & \multirow[b]{2}{*}{ No } & \multirow{2}{*}{$\begin{array}{l}\text { Stays per } 1000 \\
\text { inhabitants }\end{array}$} & \multicolumn{2}{|c|}{ Days per stays } & \multirow[b]{2}{*}{ No } & \multirow{2}{*}{$\begin{array}{l}\text { Stays per } 1000 \\
\text { inhabitants }\end{array}$} & \multicolumn{2}{|c|}{ Days per stays } \\
\hline & & & Mean & $S D$ & & & Mean & $S D$ \\
\hline Cancer (140-208) & 1669 & 30.1 & 6.6 & 7.3 & 900 & 43.8 & 10.1 & 26.3 \\
\hline Angina pectoris (413) & 787 & 14.2 & 6.7 & 4.7 & 457 & 22.2 & 6 & 5.8 \\
\hline Cardiac failure (428) & 214 & 3.9 & 10.8 & 14.7 & 149 & 7.2 & 15.8 & 62.3 \\
\hline Apoplexia cerebri $(435-436)$ & 347 & 6.3 & 13 & 14.2 & 285 & 13.9 & 29.3 & 57.7 \\
\hline Pneumonia $(480-488)$ & 480 & 8.7 & 6.7 & 6.5 & 314 & 15.3 & 10.1 & 23 \\
\hline $\begin{array}{l}\text { Asthma/chronic obstructive pulmonary disease } \\
\quad(490-497)\end{array}$ & 473 & 8.5 & 6 & 5.7 & 427 & 20.8 & 8.4 & 20.7 \\
\hline General symptoms (780) & 315 & 5.7 & 4.2 & 3.5 & 271 & 13.2 & 3.9 & 5.5 \\
\hline General abdominal symptoms (787-789) & 829 & 15 & 3.2 & 3.3 & 338 & 16.4 & 2.9 & 2.6 \\
\hline Fractures, excluding cranial (805-829) & 1297 & 23.4 & 5.9 & 7.4 & 532 & 25.9 & 9.8 & 14.6 \\
\hline $\begin{array}{l}\text { Traumas, including minor traumas, distortions, } \\
\text { commotio cerebri, intoxications }(830-849,850 \text {, } \\
905-919,939-949,960-979,996-999)\end{array}$ & 1066 & 19.2 & 4.1 & 5.6 & 671 & 32.6 & 4.1 & 8.1 \\
\hline All "GP hospital diagnoses" & 7477 & 134.9 & 6 & 7.4 & 4344 & 211.2 & 9 & 25.6 \\
\hline Other diagnoses & 15913 & 287.2 & 5.5 & 6.1 & 7701 & 374.2 & 6.9 & 24.7 \\
\hline
\end{tabular}


an independent, specific effect of GP hospitals in Finnmark.

Because of the abundant supply of GP hospitals it might have been expected that general hospital utilisation in Finnmark would be lower than in the rest of the country, but this is not the case. ${ }^{14}$ The high hospital bed capacity of Finnmark (excluding GP beds) is the probable explanation of this phenomenon. This is in accordance with studies indicating that hospital utilisation varies with bed capacity. ${ }^{15}{ }^{16}$ Our material showed differences within Finnmark consistent with this assumption. The general hospital area that has the highest admission rates also had the highest bed capacity in the general hospital. One rural municipality located equally distant from the two general hospitals made use of beds in both hospitals as well as its own GP beds. The admission rate for "GP hospital diagnoses" from this remote community was the highest among the rural municipalities, which may indicate an effect of high bed availability reducing the influence of the geographical dimension.

In addition to high admission rates, the relative abundance of hospital beds in Finnmark may result in more prolonged stays for nursing problems. The preponderance of long term stays among elderly people living in municipalities with a general hospital shows the unequal geographical distribution of this facilities. According to another study, ${ }^{1}$ stroke and fractures, two major "GP hospital diagnoses" in this study, were the most common conditions among patients with "post hospital" long term care in GP beds. This gives suport to the idea that the unequal distribution of long term care for certain conditions (table 2) is in part associated with easier access to follow up care in GP hospitals.

Reduced admissions and shorter stays in general hospitals for several diagnostic groups may indicate that GP hospitals contribute to both economic and appropriate use of resources. According to county budget data the average costs of care per day in a GP hospital is roughly $70 \%$ lower than the costs of general hospital care. The care of cancer, one of the most common diagnoses encountered in the GP beds ${ }^{1}$ may illustrate the role of the local beds. Cancer patients were given intermediate (cytostatic) treatment and terminal care in the GP hospitals.

Do GP hospitals induce a particular practice style?

Available beds, better equipment, and probably an attraction of professionals with enthusiasm for GP hospital work may facilitate a particular style of practice different from primary care elsewhere. Cooperation of general practitioners in pre- and post-hospital specialist care for conditions like cancer, fracture, stroke, and asthma are typical elements of GP hospital work in Finnmark. This would be difficult to accomplish without access to beds. Modification of practice because of access to GP beds may explain the lower general hospital utilisation from peripheral municipalities for these conditions. This is in accordance with other studies ascribing variation in hospital use
KEY POINTS

- General practioner hospitals reduce admissions and bed day utilisation in general hospitals for rural populations.

- Access to local beds is of particular importance for elderly patients for whom care and follow up close to home is preferred.

- Access to local beds is also important in rehabilitation and terminal care of certain conditions, for example, stroke, fractures, and cancer.

- Costs of care in general practioner hospitals is low compared with general hospitals.

to factors such as different medical practice, ${ }^{17} 18$ and doctors' enthusiasm for certain kinds of treatment. ${ }^{19}$

The findings of this study strongly suggest that GP hospitals in Finnmark reduce rates of admission and of occupied bed days in general hospitals. This is most evident for conditions commonly treated in GP hospitals, particularly cancer, stroke, fractures, traumas, and respiratory disorders.

Funding: this study was financially supported by "The Quality Assurance Fund" of the Norwegian Medical Association and by the Norwegian Ministry of Health and Social affairs.

Conflicts of interest: none.

1 Aaraas I. The Finnmark general practitioner hospital study. Patients characteristics, patient flow and alternative care level. Scand F Prim Health Care 1995;13:250-6.

2 Aaraas I, Søråsdekkan H. Sykestuer i Finnmark. (In Norwegian). Tromsø: University of Tromsø, Institute of community medicine, 1994

3 Dean AG, Dean JA, Coulombier D, et al. Epi Info, Version 6: a word processing, database, and statistics program for epidemiology on microcomputers. Atlanta, Georgia, USA: Centres for Disease Control and Prevention, 1994.

4 Bradford Hill A. Principles of medical statistics. 9th ed. London: The Lancet Limited, 1971.

5 Sander J. Evaluation of an internal medicine department in a general hospital (English summary). Tidsskr Nor Laegeforen 1976;96:1634-8

6 Baker JE, Goldacre M, Muir Gray JA. Community hospitals in Oxfordshire: their effect on the use of specialist inpatient services. F Epidemiol Community Health 1986;40:117-20.

7 Kyle D. Contribution of a general practitioner hospital. BMf 1971;4:348-9.

8 Cavenagh AJM. Contribution of general practitioner hospitals in England and Wales. BMF 1978;2:34-6.

9 Mamen K, Nylenna M. Patients in Norwegian cottage hospitals (English summary). Tidsskr Nor Laegeforen 1987;107: 2612-15.

10 Treasure RAR, Davies JAJ. Contribution of a general practitioner hospital: a further study. BMF 1990;300:644-6.

11 Rokkones T, Forsen L. Innleggelser $i$ sykehus - arrsaker til forskjeller mellom kommuner $i$ Møre og Romsdal (In Norwegian, ing, Statens institutt for folkehelse. Rapport nr. 4-1982.

12 Fylkesnes, K. Determinants of health care utilization - visits and referrals. Scand $\mathcal{F}$ Soc Med 1993;21:40-50.

13 Vik LJ. Patients in Norwegian general hospitals. Length of stay and patterns of use (English summary). Tidsskr Nor Laegeforen 1993;113:2423-6.

14 Solstad K, Bergsland KH, editors. Hospital services in Norway. Comparative Data for Counties and Institutions 1993 (English summary). Trondheim: SINTEF/NIS. Rapport 3/94.

5 Roemer M. Bed supply and hospital utilization: a natural experiment. Hospitals $\mathscr{\exists} A H A$ 1961;35:36-42.

16 Sanders D, Coulter A, McPherson K. Variation in hospital admission rates: a review of the literature. London: King's Fund Project Paper, Department of Health and Social Security, 1989.

17 Wennberg JE, Freeman JL, Culp WJ. Are hospital services rationed in New Haven or over-utilised in Boston? Lancet 1987;i:185-9.

$18 \mathrm{McPherson} \mathrm{K}$. International differences in medical care practice. In: Health care systems in transition. Paris: OECD practice. In: Health care systems

19 Chassin MR. Explaining geographic variations. The enthusiasm hypothesis. Med Care 1993;31 (suppl 5):YS37-44. 